\title{
Characterization in vitro and in vivo of the oxygen dependence of an enzyme/polymer biosensor for monitoring brain glucose
}

\author{
Blanaid M. Dixon ${ }^{\mathrm{a}}$, John P. Lowry ${ }^{\mathrm{b}}$, Robert D. O’Neill ${ }^{\mathrm{a}, *}$ \\ ${ }^{a}$ Department of Chemistry, University College Dublin, Belfield, Dublin 4, Ireland \\ ${ }^{\mathrm{b}}$ Department of Chemistry, National University of Ireland, Maynooth, Ireland
}

\begin{abstract}
The oxygen dependence of a first generation amperometric biosensor was investigated in vitro and in vivo by monitoring its glucose response as a function of solution $\mathrm{pO}_{2}$. The biosensor was a glucose oxidase (GOx) modified poly $(o$-phenylenediamine) coated Pt cylinder electrode (Pt/PPD/GOx) that has been designed for neurochemical analysis in vivo. Two types of oxygen probes were used: a self-calibrating commercial macroelectrode in vitro; and a carbon paste microelectrode in vivo. Calibrations in vitro showed that oxygen interference in the operation of Pt/PPD/GOx electrodes was minimal for concentrations of glucose $(\sim 0.5 \mathrm{mM})$ and oxygen $(\sim 50 \mu \mathrm{M})$ found in brain ECF. This observation was confirmed by simultaneous monitoring in vivo of brain glucose and oxygen in the awake rat. However, at levels of glucose normally found in peripheral tissues $(\sim 5 \mathrm{mM})$, the oxygen dependence was severe. We conclude that the oxygen sensitivity of Pt/PPD/GOx biosensors does not preclude their reliable use in media containing low glucose levels, such as brain ECF. (C) 2002 Elsevier Science B.V. All rights reserved.
\end{abstract}

Keywords: Poly(o-phenylenediamine); Enzyme modified electrode; Amperometry; Voltammetry in vivo; Glucose oxidase; Electropolymerization

\section{Introduction}

The incorporation of biologically active molecules into sensing devices has promoted considerable development of fast, efficient and inexpensive assays for a wide range of analytes in research, clinical, industrial and environmental applications (Braguglia, 1998; Zhang et al., 2000; Karube and Nomura, 2000; Liang et al., 2000; Wang, 2001). In particular, the immobilization of enzymes onto electrode surfaces provides biosensors that can be categorized broadly as first, second or third generation devices depending on the mode of electron transfer between the redox center of the enzyme and the electrode surface (Wang, 1993; Scheller et al., 1993). Using the flavoenzyme glucose oxidase (GOx), the majority of these sensors have focused on the amperometric detection of glucose, both as a model system and because of the importance of glucose as a target analyte (Magner, 1998).

\footnotetext{
* Corresponding author. Tel.: +353-1-716-2314/2300; fax: +353-1716-2127

E-mail address: robert.oneill@ucd.ie (R.D. O’Neill).
}

The overall enzymatic process, that is similar for many oxidases, may be written as Eq. (1) and Eq. (2):

$$
\begin{aligned}
& \beta \text {-D-glucose }+\mathrm{GOx} / \mathrm{FAD} \rightarrow \text { D-glucono- } \delta \text {-lactone } \\
& \quad+\mathrm{GOx} / \mathrm{FADH}_{2} \\
& \text { GOx } / \text { FADH }{ }_{2}+\mathrm{O}_{2} \rightarrow \mathrm{GOx} / \mathrm{FAD}+\mathrm{H}_{2} \mathrm{O}_{2} \\
& \mathrm{H}_{2} \mathrm{O}_{2} \rightarrow \mathrm{O}_{2}+2 \mathrm{H}^{+}+2 \mathrm{e}^{-}
\end{aligned}
$$

where FAD is the oxidised form of the prosthetic group, flavin adenine dinucleotide. Eq. (3) represents the electrochemical step, generating current, and is generally carried out amperometrically at relatively high applied potentials. A clear limitation of this reaction scheme (13 ) from an analytical perspective, is that the signal (Eq. (3)) may be prone to interference by the effect of changes in $\mathrm{pO}_{2}$ in Eq. (2), undermining its use to reflect glucose concentrations unambiguously. Indeed, in some situations, such as bioprocess monitoring and in vivo measurements, $\mathrm{O}_{2}$ availability may be very limited. Attempts to overcome this problem include the use of membranes (Sakamoto, 1992) and different electrode geometries (Lucisano and Gough, 1988; Pishko et al., 1991), and while many of these modifications have helped alleviate the oxygen problem, they have not succeeded in eliminating it. 
Classical, or first generation, devices involve monitoring either the consumption of $\mathrm{O}_{2}$ (Clark and Lyons, 1962) or the formation of $\mathrm{H}_{2} \mathrm{O}_{2}$ (Updike and Hicks, 1967) by the oxidase. The latter remains the most common form of biosensor despite requiring a large overpotential at which reducing agents present in the sample can contribute to the faradaic current. Although some of the problems associated with anodic $\mathrm{H}_{2} \mathrm{O}_{2}$ detection have been minimized by using electrocatalytic $\mathrm{H}_{2} \mathrm{O}_{2}$ reduction at low potentials (Gao et al., 1992; Vreeke et al., 1992; Wang et al., 1994, 1996), the question of sensitivity to $\mathrm{pO}_{2}$ appears in an additional form - the possibility of direct faradaic reduction of $\mathrm{O}_{2}$.

As an alternative approach, there has been an upsurge in the development of second generation systems in which $\mathrm{O}_{2}$ is replaced with an artificial mediator. Many such redox mediators have been used successfully, including metallocenes, quinones, ferrocyanide and tetrathiafulvalene (Di Gleria et al., 1986; Wang, 1993). The advantages of such devices are that the electrode may be operated at lower applied anodic potentials, and since molecular oxygen is not the final electron acceptor, these sensors might be expected to be relatively independent of changes in $\mathrm{pO}_{2}$. There are reports, however, where artificial mediators could not compete effectively with $\mathrm{O}_{2}$ (Razumas et al., 1993; Wilke and Muller, 1994; Martens and Hall, 1994), and the continuous leaching of potentially toxic mediator is an inherent problem for applications in vivo.

A number of laboratories have described the development and characterization of a first generation glucose sensor based on a GOx-modified poly $(o$-phenylenediamine) coated $\mathrm{Pt}(\mathrm{Pt} / \mathrm{PPD} / \mathrm{GOx})$ electrode that possesses a variety of properties indicating suitability for neurochemical applications (Sasso et al., 1990; Malitesta et al., 1990; Reynolds and Yacynych, 1993; Bartlett and Birkin, 1994; Lowry et al., 1994a). These attributes include fast response time, linearity over the relevant concentration range, effective elimination of interference by endogenous reducing agents such as ascorbic acid, freedom from protein and lipid fouling, stability in vivo, and ease of miniaturisation (O'Neill and Lowry, 2000). In a preliminary publication, we demonstrated that $\mathrm{Pt} /$ PPD/GOx sensors might also be free of $\mathrm{O}_{2}$ interference in applications both in vitro and in vivo by showing that they responded to glucose with similar sensitivity over a wide range of $\mathrm{pO}_{2}$ values in vitro (Lowry et al., 1994b). As this phenomenon has important implications both for the development of biosensors and for their operation in biological systems, where $\mathrm{O}_{2}$ availability is restricted, we examine it now in more detail. A preliminary report of some of these findings has been published (Dixon et al., 2001).

\section{Materials and methods}

\subsection{Chemicals and solutions}

The enzymes GOx from Aspergillus niger (EC 1.1.3.4, type VII-S), Ketamine and acetazolamide (Diamox) were obtained from Sigma Chemical Co. $o$-Phenylenediamine ( $o$-PD) (1,2-diaminobenzene, Sigma), $\alpha$-D- $(+)-$ glucose (Sigma), L-ascorbic acid (AA, BDH Biochemical grade), and bovine serum albumin (BSA, Armour Pharmaceutical Co. Ltd, fraction $\mathrm{V}$ from bovine plasma) were used as supplied. Carbon paste was prepared by thoroughly mixing $2.83 \mathrm{~g}$ carbon powder (UCP-1-M, Ultra Carbon Corporation, Bay City, MI) and $1.0 \mathrm{ml}$ silicone oil (Aldrich, Cat. No. 17 563-3).

A stock $1 \mathrm{M}$ solution of glucose was prepared in water, left for $24 \mathrm{~h}$ at room temperature to allow equilibration of the anomers, and then stored at $4{ }^{\circ} \mathrm{C}$. All experiments in vitro were carried out in a phosphate buffered saline (PBS) solution, pH 7.4; $\mathrm{NaCl}$ (Merck, BP USP grade, $150 \mathrm{mM}), \mathrm{NaH}_{2} \mathrm{PO}_{4}(\mathrm{BDH}$, AnalaR grade, $40 \mathrm{mM}$ ) and $\mathrm{NaOH}$ (BDH, GPR grade, $40 \mathrm{mM}$ ). A $200 \mathrm{U} / \mathrm{ml}$ solution of GOx was prepared by dissolving $15 \mathrm{mg}$ in $10 \mathrm{ml}$ of PBS. The $300 \mathrm{mM} o$-PD monomer solution was prepared using $0.32 \mathrm{~g}$ of $o$-PD and $50 \mathrm{mg}$ of BSA in $10 \mathrm{ml}$ of PBS and sonicating at $25{ }^{\circ} \mathrm{C}$ for 30 min.

\subsection{Instrumentation and software}

Experiments were microcomputer controlled with data collection accomplished using either a Biodata Microlink interface or a National Instruments (NI, Austin, TX) AT-MIO-16 data acquisition board linked to a low-noise, low-damping potentiostat (Biostat II, Electrochemical and Medical Systems, Newbury, UK). The 2-channel configuration of the potentiostat allowed different potential waveforms to be applied to two working electrodes simultaneously. In-house software was written in QuickBASIC (version 4.0) and NI LabWindows (version 2.1) QuickBASIC environments to perform all amperometric experiments and to collect, plot, and do a preliminary analysis of the data.

\subsection{Working electrode preparation}

The fabrication of the working electrode biosensors has been described in detail recently (O'Neill et al., 1998; Lowry et al., 1998b). Briefly, cylinders ( $\sim 1 \mathrm{~mm}$ long) of freshly cut Teflon-insulated $\mathrm{Pt}$ wire ( $60 \mu \mathrm{m}$ radius) were dipped into a $200 \mathrm{U} / \mathrm{ml}$ solution of GOx to allow adsorption of the enzyme, and then removed to dry. The enzyme-coated wire was then immersed into PBS containing the monomer and BSA, and electropolymerisation carried out at $700 \mathrm{mV}$ vs. saturated calomel 
electrode (SCE) for $15 \mathrm{~min}$ to produce $\mathrm{Pt} / \mathrm{PPD} / \mathrm{GOx}$ sensors.

The carbon paste electrodes (CPEs) for the detection of solution $\mathrm{O}_{2}$ in vivo were made from Teflon-coated silver wire $(200 \mu \mathrm{m}$ internal diameter, $280 \mu \mathrm{m}$ external diameter). The Teflon insulation was slid along the wire to create an approximately $1-\mathrm{mm}$ deep cavity that was packed with carbon paste using a bare silver wire as plunger. When not in use all electrodes were stored in PBS at $4{ }^{\circ} \mathrm{C}$.

A self-calibrating commercial membrane-covered amperometric oxygen sensor ( $\sim 1 \mathrm{~cm}$ diameter) was used to quantify solution oxygen concentration in vitro. The model used was a CellOx 325 connected to an Oxi 340A meter (Wissenschaftlich-Technische Werkstätten GmbH from Carl Stuart Ltd, Dublin, Ireland), incorporating a temperature probe for automatic compensation. Reliable quantification of $\mathrm{O}_{2}$ using this device required constant stirring of the solution at a rate of $\sim 2 \mathrm{~Hz}$. The sensor range was $0.0-199.9 \% \mathrm{O}_{2}(100 \%$ corresponding to air saturation) with a resolution of $0.1 \%$. For some purposes, this percentage was converted to an estimated concentration of $\mathrm{O}_{2}$, taking $200 \mu \mathrm{M}$ to correspond to 100\% (Bourdillon et al., 1982; Zhang and Wilson, 1993).

\subsection{Amperometric experiments in vitro}

All experiments in vitro were performed in a standard three-electrode glass electrochemical cell containing 20 $\mathrm{ml}$ PBS thermostated at $25.0 \pm 0.5^{\circ} \mathrm{C}$. A SCE was used as the reference electrode, and a large silver wire, isolated in a compartment containing PBS, served as the auxiliary electrode. The applied potential for amperometric studies was $+700 \mathrm{mV}$ vs. SCE unless stated otherwise, which is the value generally used for $\mathrm{H}_{2} \mathrm{O}_{2}$ detection. To avoid contamination by oxygen, the electrochemical cell was contained within an Atmosbag $^{\text {TM }}$ (Sigma), a two-hand 0.003-in. gauge polyethylene bag that was sealed and filled with $\mathrm{N}_{2}$ during experiments, inflating to a volume of 2801 .

The addition of glucose was not carried out until the electrodes were well settled giving a steady background in air-saturated PBS. After the addition of a single aliquot of glucose, the bag was sealed and high-grade $\mathrm{N}_{2}$ $\left(<5 \mathrm{ppm} \mathrm{O}_{2}\right)$ introduced. The time required to achieve minimal $\mathrm{O}_{2}$ concentrations in solution $(<1 \mu \mathrm{M})$ was approximately $3 \mathrm{~h}$ (Fig. 1A), even at a driving pressure of $1 \mathrm{~kg} / \mathrm{cm}^{2}$ and an open nipple valve on the $\mathrm{N}_{2}$ cylinder. Oxygen sensor data and biosensor data were recorded simultaneously through the transition from air saturation to $\mathrm{N}_{2}$ saturation and/or vice versa, the biosensor data normalized relative to the respective air saturation value, and plotted against the measured concentration of $\mathrm{O}_{2}$.

To calibrate the CPEs used for oxygen detection in vivo, differential pulse amperometry (DPA, one pulse

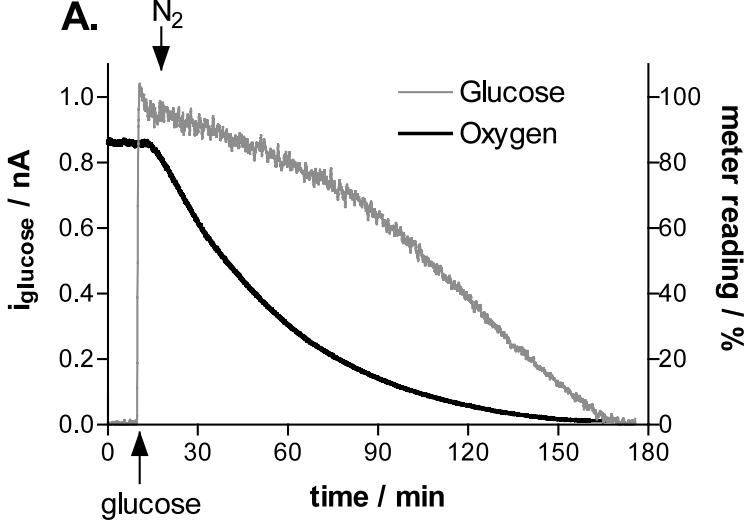

B.

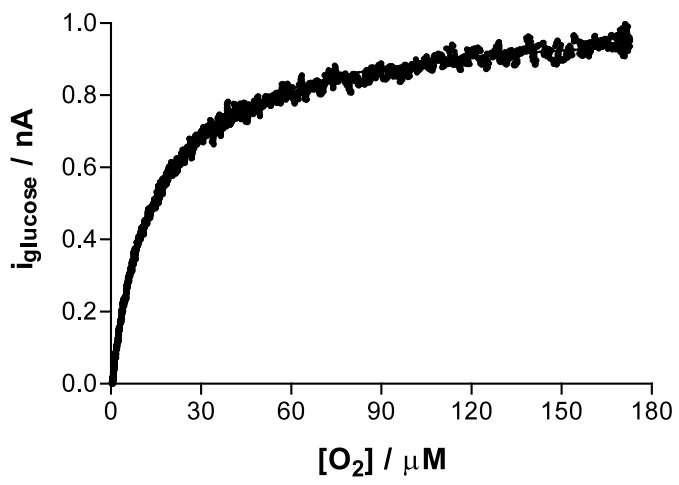

Fig. 1. (A) Example of raw data for oxygen (CellOx sensor, black, right axis) and glucose (Pt/PPD/GOx biosensor, grey, left axis) recorded in vitro. $0.5 \mathrm{mM}$ glucose was injected into PBS, containing ambient levels of air, at the first arrow. Nitrogen was then introduced (second arrow) into the AtmosBag surrounding the electrochemical cell. Removal of $\mathrm{O}_{2}$ followed a one-phase exponential decay with a half-life of $35 \pm 5 \min (n=4)$. (B) Glucose-oxygen correlation plot for data shown in A above. Non-linear regression using Eq. (4), gave $K_{\mathrm{m}}\left(\mathrm{O}_{2}\right)=15 \pm 1 \mu \mathrm{M}$ and $i_{\max }=1.0 \pm 0.1 \mathrm{nA}$, with $R^{2}>0.996$.

pair: -150 to $-350 \mathrm{mV}$ and -350 to $-550 \mathrm{mV}$ from a resting potential of $-150 \mathrm{mV}$ ) was used in vitro as described recently (Lowry et al., 1996, 1997). The CPEs were calibrated after removal from the brain because implantation affects the sensitivity of these paste electrodes (O’Neill, 1993; Kane et al., 1998). Residual DPA current recorded in $\mathrm{N}_{2}$-saturated PBS, due to uncompensated capacitance and surface redox processes, was subtracted from the current recorded in air-saturated $(200 \mu \mathrm{M})$ and $\mathrm{O}_{2}$-saturated $(1.26 \mathrm{mM})$ buffer (Bourdillon et al., 1982; Zhang and Wilson, 1993).

Non-linear regression analysis of the oxygen dependence of the glucose signal was carried out using a software package (Prism, GraphPad Software, Inc., San Diego, CA) and a Michaelis-Menten type equation (Eq. (4), where $i$ is the biosensor signal). The reactant, sub, is usually the enzyme substrate (glucose, Eq. (1)) or, as in this study, the co-substrate (dioxygen, Eq. (2)) whose concentration is being varied, and $K_{\mathrm{m}}$ is an apparent Michaelis-Menten constant. When sub is the target 
analyte, a large value of $K_{\mathrm{m}}$ is beneficial ( $i$ is then linear in [sub]). However, when sub is a possible interference species, a small value of $K_{\mathrm{m}}$ is advantageous because $i$ is then independent of [sub] except at very low [sub] values; Fig. 1B.

$$
i=\frac{i_{\max }}{1+\frac{K_{\mathrm{m}, \mathrm{sub}}}{[\mathrm{sub}]}}
$$

\subsection{Experiments in vivo}

Male Sprague-Dawley rats weighing 200-300 g were anaesthetised and implanted with two electrochemical sensors as described previously (Lowry and Fillenz, 1997). The Pt/PPD/GOx electrode was implanted in the right striatum at co-ordinates (skull levelled between bregma and lambda): $\mathrm{A} / \mathrm{P}+1.0$ from bregma, $\mathrm{M} / \mathrm{L}+2.5$, and $\mathrm{D} / \mathrm{V}-5.0$ (from dura). A CPE was implanted in the left striatum at corresponding co-ordinates. The reference electrode ( $8 \mathrm{~T}$ silver wire, $200-\mu \mathrm{m}$ bare diameter) was placed in the cortex, the auxiliary electrode (8T silver wire) placed between the skull and dura, and an earth wire (8T silver wire) attached to one of the support screws. The electrodes were attached to a socket, and fixed to the skull with screws and dental acrylate. Animals were allowed $24 \mathrm{~h}$ to recover after surgery. All procedures were specifically licensed under the Animals (Scientific Procedures) Act, 1986 (UK) and involved simultaneous monitoring of $\mathrm{O}_{2}$ using DPA with the CPE (Lowry et al., 1996, 1997) and of glucose using amperometry with the Pt/PPD/GOx sensor held at +700 mV (Lowry et al., 1994a, 1998b).

All data are reported as mean \pm SEM with $n=$ number of electrodes. The statistical significance of all drug effects was estimated using Student's two-tailed paired $t$-tests on the absolute currents.

\section{Results and discussion}

\subsection{Oxygen detection in vitro}

A recent report on the oxygen dependence of $\mathrm{Pt} / \mathrm{PPD} /$ GOx biosensors (Wang and Lu, 1998) prompted us to re-appraise our previous conclusion, based on a preliminary pilot study (Lowry et al., 1994b), that these devises were essentially free of oxygen interference at physiologically relevant levels of $\mathrm{O}_{2}$. The more rigorous quantification of solution oxygen achieved here, using the self-calibrating CellOx 325 electrode, showed that in our previous experimental design (cell open to the atmosphere), the solution oxygen concentration did not fall below $36 \pm 5 \mu \mathrm{M}(n=5)$, even after extensive bubbling of the PBS with nitrogen, and explains the discrepancies between the two reports. To confirm the ability of the commercial $\mathrm{O}_{2}$ sensor/meter system to quantify zero $\mathrm{pO}_{2}$ levels, $1 \mathrm{mM}$ of the $\mathrm{O}_{2}$-scavenger, sodium dithionite, was added to the $\mathrm{N}_{2}$-challenged PBS. When the dithionite was added, the reading dropped to a value not significantly greater than zero $(\sim 0.5 \mu \mathrm{M}$ $\mathrm{O}_{2}$ ).

To avoid this oxygen contamination, an AtmosBag was used to isolate the cell from the atmosphere in all subsequent experiments in vitro, and nitrogen gas introduced directly into the bag (not bubbled through the solution) to avoid turbulent convection. Fig. 1A shows the time course for removal of oxygen from the PBS and the effectiveness of the bag in preventing oxygen contamination in the cell. Removal of $\mathrm{O}_{2}$ had a half-life of $35 \pm 5 \mathrm{~min}(n=4)$ and sub-micromolar levels of $\mathrm{O}_{2}$ could be achieved after $\sim 3-4$ h of flushing with nitrogen.

\subsection{Oxygen-sensitivity of Pt/PPD/GOx responses to glucose in vitro}

The glucose calibration profile and sensitivity of this type of enzyme/polymer-based sensor have been reported extensively (Sasso et al., 1990; Malitesta et al., 1990; Reynolds and Yacynych, 1993; Bartlett and Birkin, 1994; Lowry et al., 1994a). Because stirring was necessary in the present experiments to allow the CellOx $\mathrm{O}_{2}$ probe to function quantitatively, and because convection affects the glucose current (Bartlett and Whitaker, 1987), the absolute size of the glucose signal is neither comparable to previous studies nor of much relevance. The focus here is the effect of oxygen on the glucose response, and so a normalized current was calculated, using the air-saturated current for each glucose concentration as $100 \%$.

Fig. 1A shows an example of the absolute current response of a Pt/PPD/GOx electrode to $0.5 \mathrm{mM}$ glucose in air-saturated stirred PBS. When oxygen was then removed from the solution, both the $\mathrm{O}_{2}$ and biosensor signals decreased, albeit with different time courses, and approached zero as oxygen was completely removed from the system, as expected from Eqs. (2) and (3). Fig. $1 \mathrm{~B}$ shows the glucose $-\mathrm{O}_{2}$ correlation plot constructed from the raw data in Fig. 1A; the plot was hyperbolic (Eq. (4)) with $K_{\mathrm{m}}\left(\mathrm{O}_{2}\right)=15 \pm 1 \mu \mathrm{M}$ and $R^{2}>0.996$. The $0.5 \mathrm{M}$ glucose current, therefore, was effectively insensitive to changes in $\mathrm{O}_{2}$ levels above $\sim 40 \mu \mathrm{M} \mathrm{O}_{2}$, but the sensitivity to $\mathrm{O}_{2}$ increased below this level.

The turnover of $\mathrm{O}_{2}$ in the polymer/enzyme composite membrane (Eq. (2)) depends on the rate at which glucose binds to the enzyme (Eq. (1)), i.e., on the concentration of glucose. We therefore carried out experiments similar to those in Fig. 1A over a range of glucose concentrations $(0.5,1.0,2.5,5.0,7.5$ and 10.0 


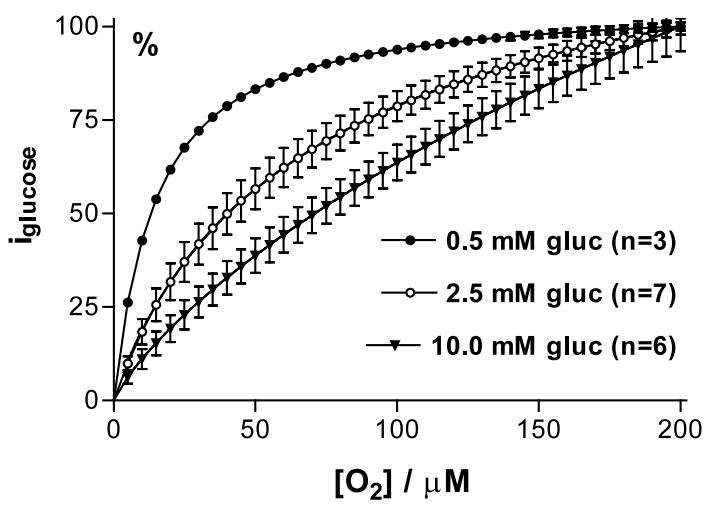

Fig. 2. Examples of averaged normalized glucose-oxygen correlation plots (Fig. 1) for three of the six concentrations of glucose studied over the relevant range of $\mathrm{O}_{2}$ concentration $\left(\mathrm{N}_{2}\right.$ saturation to air saturation) showing the increased sensitivity of the biosensor signal to solution $\mathrm{pO}_{2}$ as the concentration of glucose was increased. Non-linear regression plots shown were obtained using Eq. (4). Averaged $K_{\mathrm{m}}$ values for the individual plots are presented in Fig. 3.

$\mathrm{mM}$ ), and analysed the results as in Fig. 1B. For clarity, Fig. 2 shows only the glucose- $\mathrm{O}_{2}$ correlation plots of averaged normalized data for $0.5,2.5$ and $10.0 \mathrm{mM}$ glucose. As predicted, the $\mathrm{O}_{2}$ dependence became more acute at higher glucose concentrations. For $10 \mathrm{mM}$ glucose, a level not much greater than the normoglycemic value in human blood (Eyre et al., 1994) and less than that observed under hyperglycemic diabetic conditions (Hofer and Lanier, 1991), the $\mathrm{O}_{2}$ dependence was close to maximal with a $K_{\mathrm{m}}\left(\mathrm{O}_{2}\right)=173 \pm 47 \mu \mathrm{M}(n=6)$. The Pt/PPD/GOx sensor design would therefore not be suitable for monitoring blood glucose in vivo. Although the trend in $K_{\mathrm{m}}\left(\mathrm{O}_{2}\right)$ from 0 to $10 \mathrm{mM}$ glucose shown in Fig. 3A demonstrates a high $\mathrm{O}_{2}$ sensitivity even at moderate glucose levels, the question remained whether $\mathrm{Pt} / \mathrm{PPD} / \mathrm{GOx}$ electrodes might be suitable for monitoring brain glucose, where the estimated level is much lower than in blood. ECF glucose in rat striatum has been determined by both quantitative microdialysis: $350 \pm 20 \mu \mathrm{M}$ (Fray et al., 1997), 350 $\pm 16 \mu \mathrm{M}$ (Lowry et al., 1998a) and $710 \mu \mathrm{M}$ (McNay et al., 2001) and biosensor data: 300-400 $\mu \mathrm{M}$ (Lowry and Fillenz, 2001) in the awake rat.

Although $\mathrm{O}_{2}$ ECF levels farthest from blood brain capillaries can be as low as $5 \mu \mathrm{M}$ (Siesjo, 1978), electrodes the size of CPEs and Pt/PPD/GOx sensors sample the average tissue ECF concentration, estimated at $\sim 50 \mu \mathrm{M}$ (Nair et al., 1987; Murr et al., 1994). We therefore calculated the percentage $\mathrm{O}_{2}$ interference in the glucose signals at $50 \mu \mathrm{M} \mathrm{O}_{2}$ per micromolar change in $\mathrm{O}_{2}$ concentration $\left(S_{\%}\right)$, i.e., the tangential slope of plots similar to those in Fig. 1B determined at $50 \mu \mathrm{M}$ $\mathrm{O}_{2}$. The results of this analysis are shown in Fig. 3B. The data points were consistent with both linear (not shown) and hyperbolic fits that were distinguished only by their behaviour as the concentration of glucose approached

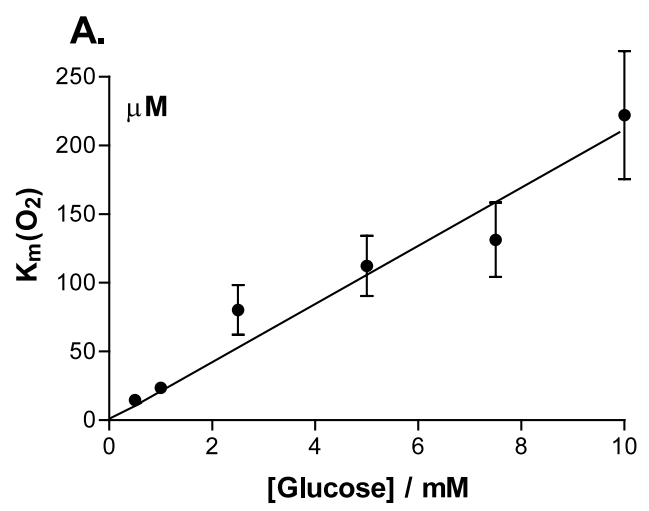

B.

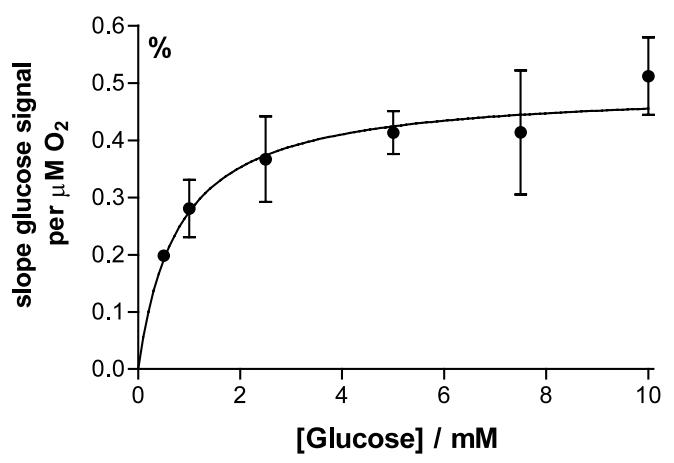

Fig. 3. (A) A plot of the average $K_{\mathrm{m}}\left(\mathrm{O}_{2}\right)$ values vs. glucose concentration, obtained using Eq. (4) and glucose-oxygen correlation data similar to that shown in Fig. 1B, and linear regression analysis $\left(R^{2}>0.96\right)$, showing the increased sensitivity of the biosensor signal to solution $\mathrm{pO}_{2}$ as the concentration of glucose was increased. (B) The average percentage $\mathrm{O}_{2}$ interference in the glucose signals at $50 \mu \mathrm{M} \mathrm{O}$ per micromolar change in $\mathrm{O}_{2}$ concentration $\left(S_{\%}\right)$, obtained by averaging the tangential slopes (at $50 \mu \mathrm{M} \mathrm{O}_{2}$ ) of plots similar to those in Fig. 1B. An hyperbolic curve was fitted to allow $S_{\%}$ to approach zero as the concentration of glucose approaches zero (see text for discussion).

zero. Unfortunately, because of the stirring needed for the determination of $\mathrm{O}_{2}$ and the long time needed to remove $\mathrm{O}_{2}$ from the system ( $\sim 3$ h, Fig. 1), sufficiently stable glucose signals for concentrations below $0.5 \mathrm{mM}$ were not achievable in vitro. However, one can argue that as the concentration of glucose, and therefore the turnover of enzyme (Eq. (1)), approach zero, the Pt/ PPD/GOx signal would be the same for 49 and $51 \mu \mathrm{M}$ $\mathrm{O}_{2}$; i.e., $S_{\%}$ should also approach zero. Therefore the hyperbolic fit is the better one, a conclusion supported by the finding that $K_{\mathrm{m}}\left(\mathrm{O}_{2}\right)$ approaches zero under these conditions (Fig. 3A). Using this fit, the extrapolated value of $S_{\%}$ for $350 \mu \mathrm{M}$ glucose was calculated as $0.14 \%$ per $\mu \mathrm{M} \mathrm{O}_{2}$. This suggests that increases in brain $\mathrm{pO}_{2}$ would have negligible impact $\left(<0.14 \%\right.$ per $\left.\mu \mathrm{M} \mathrm{O}_{2}\right)$ on the glucose signal recorded in brain ECF and that decreases in $\mathrm{pO}_{2}$ would only be significant if the tissue $\mathrm{O}_{2}$ levels became severely depleted. The non-linearity of these functions, however, preclude the use of a single number to define the interference of $\mathrm{O}_{2}$ in measuring 


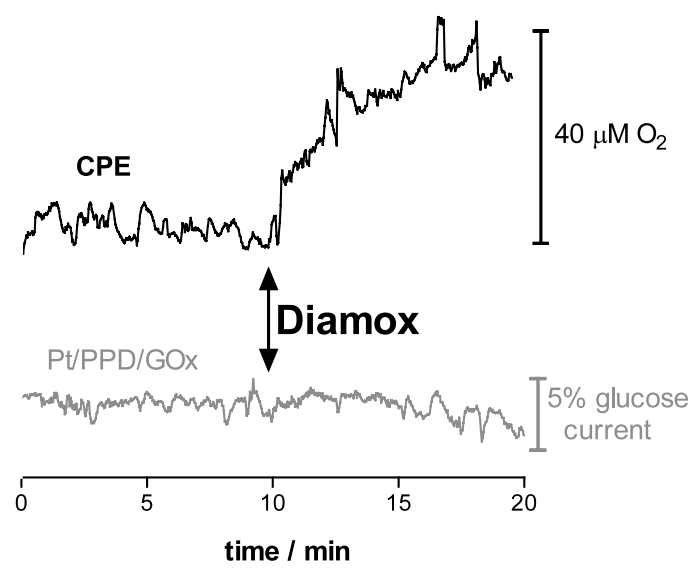

Fig. 4. The effect of systemic administration of the carbonic anhydrase inhibitor (Diamox, $50 \mathrm{mg} / \mathrm{kg}$, i.p.) on the $\mathrm{O}_{2}$ and glucose signals monitored simultaneously in vivo in rat brain (striatum). The $\mathrm{O}_{2}$ current (black) was recorded using DPA with a CPE in the left striatum while glucose (grey) was detected using amperometry at +700 $\mathrm{mV}$ with a Pt/PPD/GOx electrode in the right striatum.

glucose, and so this conclusion was tested by monitoring the $\mathrm{Pt} / \mathrm{PPD} / \mathrm{GOx}$ glucose signal in brain ECF and manipulation brain $\mathrm{pO}_{2}$.

\subsection{Oxygen-sensitivity of Pt/PPD/GOx responses to glucose in vivo}

The carbonic anhydrase inhibitor acetazolamide (Diamox) administered systemically has been shown to increase $\mathrm{pO}_{2}$ in brain ECF (Clark and Lyons, 1965). Fig. 4 shows the effect of this drug $(50 \mathrm{mg} / \mathrm{kg}$, i.p. $)$ on the glucose and $\mathrm{O}_{2}$ signals recorded simultaneously in rat striatum. As expected, Diamox increased $\mathrm{O}_{2}$ levels in the ECF. Calibration of the CPEs recovered after the experiments allowed us to estimate this increase as $40 \pm$ $12 \mu \mathrm{M}(n=5, P<0.03) 10$ min after the injection, which is similar to the increase observed following mild stress (Lowry et al., 1996). There was no corresponding change in the glucose signal at this time: $9.7 \pm 3.6 \mathrm{nA}$ before and $8.9 \pm 2.9 \mathrm{nA}$ after injection; $n=5, P>0.35$, paired $t$-test; see Fig. 4 . Thus, although the estimated concentration of brain extracellular $\mathrm{O}_{2}$ is relatively low at approximately $50 \mu \mathrm{M}$ (Nair et al., 1987; Murr et al., 1994), significant increases in its concentration did not affect the glucose current, supporting the $\mathrm{O}_{2}$ interference analysis presented in Section 3.2.

A more critical test of the reliability of the Pt/PPD/ GOx sensors to monitor glucose in the presence of fluctuating $\mathrm{pO}_{2}$ is the effect on the glucose signal of decreasing ECF $\mathrm{pO}_{2}$. Anaesthetic doses of Ketamine have been shown recently to cause biphasic changes in brain ECF $\mathrm{pO}_{2}$ (Lowry and Fillenz, 2001), and so we used this drug to investigate further the $\mathrm{O}_{2}$ interference question. Ketamine ( $200 \mathrm{mg} / \mathrm{kg}$, i.p., see Fig. 5) caused a decrease in the initial phase of $32 \pm 9 \mu \mathrm{M}(n=7, P<$ 0.02) in striatal $\mathrm{O}_{2} 20 \mathrm{~min}$ after the injection. At that time, there was no significant change in the biosensor signal: $10.6 \pm 2.7 \mathrm{nA}$ before and $10.6 \pm 2.8 \mathrm{nA} 20 \mathrm{~min}$ after injection $(n=6, P>0.99$, paired $t$-test). Thereafter, the glucose and $\mathrm{O}_{2}$ signals changed in opposite directions (Fig. 5), reflecting physiological phenomena and demonstrating further the independence of the glucose signal from oxygen interference. These findings suggest that even large decreases in $\mathrm{pO}_{2}(\sim 60 \%$ based on present estimates of average $\mathrm{pO}_{2}$ values and postimplant calibration data) do not affect the ability of $\mathrm{Pt} /$ PPD/GOx electrodes to monitor glucose reliably in brain ECF in vivo.

\section{Conclusions}

The in vitro and in vivo studies on the $\mathrm{O}_{2}$ dependence of $\mathrm{Pt} / \mathrm{PPD} / \mathrm{GOx}$ sensors reported here are internally consistent and indicate that these biosensors can be used reliably in brain ECF to monitor glucose even when there are large fluctuations in $\mathrm{pO}_{2}$. The main factor enabling this functionality is the relatively low concentration of glucose in brain ECF compared with other tissues, such as blood and subcutaneous fat where the levels of glucose could prevent its reliable quantification using these devices. It remains to be seen whether the $\mathrm{O}_{2}$ insensitivity of $\mathrm{Pt} / \mathrm{PPD} / \mathrm{GOx}$ electrodes in the brain extends to lower (ischemic) levels of $\mathrm{pO}_{2}$, and to

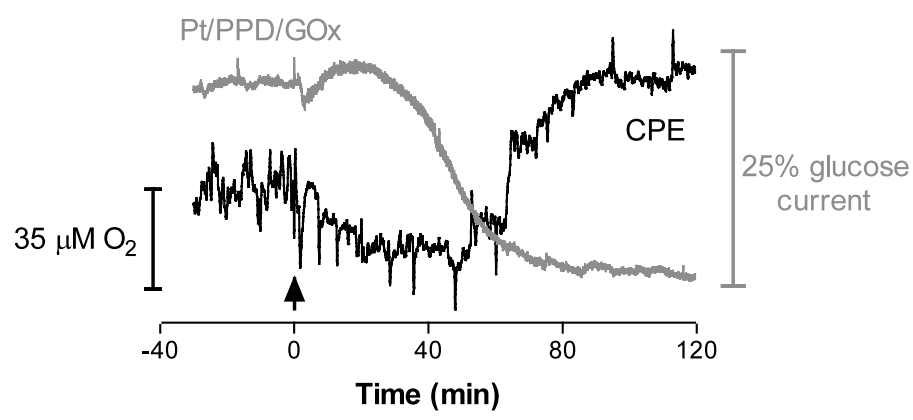

Fig. 5. The effect of systemic administration of an anaesthetic dose of Ketamine (200 mg/kg, i.p. at the arrow) on the $\mathrm{O}_{2}$ and glucose signals monitored simultaneously in vivo in rat brain. The $\mathrm{O}_{2}$ current (black) was recorded using DPA with a CPE in the left striatum while glucose (grey) was detected using amperometry at $+700 \mathrm{mV}$ with a Pt/PPD/GOx electrode in the right striatum. 
electrodes incorporating other enzymes, such as glutamate and lactate oxidases.

\section{Acknowledgements}

We thank Enterprise Ireland for grants under the Basic Research Grants Scheme (SC/98/450 and SC/99/ 149), and the Health Research Board (EQN 12/2000), U.C.D. and N.U.I., Maynooth for financial support. J.P.L. gratefully acknowledges the European Commission for a research training fellowship under the Human Capital and Mobility programme (Grant No. ERB CHB ICT94 1353).

\section{References}

Bartlett PN, Birkin PR. A microelectrochemical enzyme transistor responsive to glucose. Anal Chem 1994;66:1552-9.

Bartlett PN, Whitaker RG. Electrochemical immobilization of enzymes. Part II. Glucose oxidase immobilized in poly- $N$-methylpyrrole. J Electroanal Chem 1987;224:37-48.

Bourdillon C, Thomas V, Thomas D. Electrochemical study of Dglucose oxidase autoinactivation. Enzyme Microb Technol 1982;4:175-80.

Braguglia CM. Biosensors: an outline of general principles and application. Chem Biochem Eng Q 1998;12:183-90.

Clark LC, Jr., Lyons C. Electrode systems for continuous monitoring in cardiovascular surgery. Ann NY Acad Sci 1962;102:29-45.

Clark LC, Jr., Lyons C. Studies of a glassy carbon electrode for brain polarography with observations on the effect of carbonic anhydrase inhibition. Ala J Med Sci 1965;2:353-9.

Di Gleria K, Hill HAO, McNeil CJ, Green MJ. Homogeneous ferrocene-mediated amperometric immunoassay. Anal Chem 1986;58:1203-5.

Dixon BM, Lowry JP, O’Neill RD. Oxygen dependence of an enzyme/ polymer biosensor designed for brain glucose detection in vivo. In: O'Connor WT, Lowry JP, O'Connor JJ, O'Neill RD, editors. Monitoring molecules in neuroscience. Dublin: University College Dublin, 2001:53-4.

Eyre JA, Stuart AG, Forsyth RJ, Heaviside D, Bartlett K. Glucose export from the brain in man: evidence for a role for astrocytic glycogen as a reservoir of glucose for neural metabolism. Brain Res 1994;635:349-52.

Fray AE, Boutelle M, Fillenz M. Extracellular glucose turnover in the striatum of unanaesthetized rats measured by quantitative microdialysis. J Physiol (London) 1997;504:721-6.

Gao ZQ, Ivaska A, Li P, Lui KZ, Yang JJ. Electrocatalysis and flowinjection analysis of hydrogen peroxide at a chemically modified electrode. Anal Chim Acta 1992;259:211-8.

Hofer RE, Lanier WL. The effects of insulin infusion on plasma and brain glucose in hyperglycemic diabetic rats: a comparison with placebo-treated diabetic and nondiabetic rats. Anesthesiology 1991;75:673-8.

Kane DA, O'Neill RD. Major differences in the behaviour of carbon paste and carbon fibre electrodes in a protein-lipid matrix: implications for voltammetry in vivo. Analyst 1998;123:2899-903.

Karube I, Nomura Y. Enzyme sensors for environmental analysis. J Mol Catal B - Enz 2000;10:177-81.

Liang LF, Li YT, Yang VC. Biomedical application of immobilized enzymes. J Pharm Sci 2000;89:979-90.
Lowry JP, Boutelle MG, Fillenz M. Measurement of brain tissue oxygen at a carbon paste electrode can serve as an index of increases in regional cerebral blood flow. J Neurosci Methods 1997;71:177-82.

Lowry JP, Boutelle MG, O’Neill RD, Fillenz M. Characterization of carbon paste electrodes in vitro for simultaneous amperometric measurement of changes in oxygen and ascorbic acid concentrations in vivo. Analyst 1996;121:761-6.

Lowry JP, Fillenz M. Evidence for uncoupling of oxygen and glucose utilization during neuronal activation in rat striatum. J Physiol (London) 1997;498:497-501.

Lowry JP, Fillenz M. Real-time monitoring of brain energy metabolism in vivo using microelectrochemical sensors: the effects of anesthesia. Bioelectrochemistry 2001;54:39-47.

Lowry JP, McAteer K, El Atrash SS, Duff A, O'Neill RD. Characterization of glucose oxidase-modified poly(phenylenediamine)-coated electrodes in vitro and in vivo: homogeneous interference by ascorbic acid in hydrogen peroxide detection. Anal Chem 1994a;66:1754-61.

Lowry JP, McAteer K, El Atrash SS, O'Neill RD. Efficient glucose detection in anaerobic solutions using an enzyme-modified electrode designed to detect $\mathrm{H}_{2} \mathrm{O}_{2}$ : implications for biomedical applications. J Chem Soc Chem Commun 1994b;21:2483-4.

Lowry JP, Miele M, O’Neill RD, Boutelle MG, Fillenz M. An amperometric glucose-oxidase/poly( $o$-phenylenediamine) biosensor for monitoring brain extracellular glucose: in vivo characterisation in the striatum of freely-moving rats. J Neurosci Methods 1998b; 79:65-74.

Lowry JP, O’Neill RD, Boutelle MG, Fillenz M. Continuous monitoring of extracellular glucose concentrations in the striatum of freely moving rats with an implanted glucose biosensor. J Neurochem 1998a;70:391-6.

Lucisano JY, Gough DA. Transient response of the two-dimensional glucose sensor. Anal Chem 1988;60:1272-81.

Magner E. Trends in electrochemical biosensors. Analyst 1998; 123:1967-70.

Malitesta C, Palmisano F, Torsi L, Zambonin PG. Glucose fastresponse amperometric sensor based on glucose oxidase immobilized in an electropolymerized poly $(o$-phenylenediamine $)$ film. Anal Chem 1990;62:2735-40.

Martens N, Hall EAH. Model for an immobilized oxidase enzyme electrode in the presence of two oxidants. Anal Chem 1994;66:2763-70.

McNay EC, McCarty RC, Gold PE. Fluctuations in brain glucose concentration during behavioral testing: dissociations between brain areas and between brain and blood. Neurobiol Learn Memory 2001;75:325-37.

Murr R, Berger S, Schuerer L, Peter K, Baethmann A. A novel, remote-controlled suspension device for brain tissue $\mathrm{PO}_{2}$ measurements with multiwire surface electrodes. Pflugers Arch 1994;426:348-50.

Nair PK, Buerk DG, Halsey JH, Jr.. Comparison of oxygen metabolism and tissue $\mathrm{pO}_{2}$ in cortex and hippocampus. Stroke 1987;18:616-22.

O'Neill RD. Sensor-tissue interactions in neurochemical analysis with carbon paste electrodes in vivo. Analyst 1993;118:433-8.

O'Neill RD, Lowry JP. Voltammetry in vivo for chemical analysis of the living brain. In: Meyers R, editor. Encyclopedia of analytical chemistry. Chichester: Wiley, 2000:676-709.

O'Neill RD, Lowry JP, Mas M. Monitoring brain chemistry in vivo: voltammetric techniques, sensors and behavioral applications. Crit Rev Neurobiol 1998;12:69-127.

Pishko MV, Michael AC, Heller A. Amperometric glucose microelectrodes prepared through immobilization of glucose oxidase in redox hydrogels. Anal Chem 1991;63:2268-72. 
Razumas V, Kulys J, Knichel M, Wiemhofer HD, Gopel W. Monoalkylferrocene-mediated amperometric enzyme electrodes for glucose determination. Electroanalysis 1993;5:399-404.

Reynolds ER, Yacynych AM. Platinized carbon ultramicroelectrodes as glucose biosensors. Electroanalysis 1993;5:405-11.

Sakamoto N. Effect of enzyme concentration on the dynamic behavior of a membrane-bound enzyme system. J Membr Sci 1992;70:23747.

Sasso SV, Pierce RJ, Walla R, Yacynych AM. Electropolymerized 1,2diaminobenzene as a means to prevent interferences and fouling and to stabilize immobilized enzyme in electrochemical biosensors. Anal Chem 1990;62:1111-7.

Scheller F, Kirstein D, Schubert F, Pfeiffer D, McNeil C. Enzymes in electrochemical biosensors. Russ J Electrochem 1993;29:1334-8.

Siesjo BK. Brain energy metabolism. Chichester: Wiley, 1978.

Updike SJ, Hicks GP. The enzyme electrode. Nature (London) 1967;214:986-8.

Vreeke M, Maidan R, Heller A. Hydrogen peroxide and betanicotinamide adenine dinucleotide sensing amperometric electrodes based on electrical connection of horseradish peroxidase redox centers to electrodes through a 3-dimensional electron relaying polymer network. Anal Chem 1992;64:3084-90.

Wang J. Electroanalysis and biosensors. Anal Chem 1993;65:R450-3.

Wang J. Glucose biosensors: 40 years of advances and challenges. Electroanalysis 2001;13:983-8.

Wang J, Liu J, Chen L, Lu F. Highly selective membrane-free, mediator-free glucose biosensor. Anal Chem 1994;66:3600-3.

Wang J, Lu F. Oxygen-rich oxidase enzyme electrodes for operation in oxygen-free solutions. J Am Chem Soc 1998;120:1048-50.

Wang J, Rivas G, Chicharro M. Iridium-dispersed carbon paste enzyme electrodes. Electroanalysis 1996;8:434-7.

Wilke D, Muller H. Preparation and analytical testing of mediator containing photolithographically patterned enzyme membrane electrodes. Fresenius J Anal Chem 1994;349:661-5.

Zhang S, Wright G, Yang Y. Materials and techniques for electrochemical biosensor design and construction. Biosensors Bioelectron 2000;15:273-82.

Zhang YN, Wilson GS. In vitro and in vivo evaluation of oxygen effects on a glucose oxidase based implantable glucose sensor. Anal Chim Acta 1993;281:513-20. 